\title{
Patient Awareness and Quality of Oral Surgery Referrals to Specialist Practice
}

DOI:

10.1111/ors. 12467

\section{Document Version}

Accepted author manuscript

Link to publication record in Manchester Research Explorer

\section{Citation for published version (APA):}

Jadun, S., Syed, N., Drabu, T., \& Yates, J. (2020). Patient Awareness and Quality of Oral Surgery Referrals to Specialist Practice. Oral Surgery. https://doi.org/10.1111/ors.12467

\section{Published in:}

Oral Surgery

\section{Citing this paper}

Please note that where the full-text provided on Manchester Research Explorer is the Author Accepted Manuscript or Proof version this may differ from the final Published version. If citing, it is advised that you check and use the publisher's definitive version.

\section{General rights}

Copyright and moral rights for the publications made accessible in the Research Explorer are retained by the authors and/or other copyright owners and it is a condition of accessing publications that users recognise and abide by the legal requirements associated with these rights.

\section{Takedown policy}

If you believe that this document breaches copyright please refer to the University of Manchester's Takedown Procedures [http://man.ac.uk/04Y6Bo] or contact uml.scholarlycommunications@manchester.ac.uk providing relevant details, so we can investigate your claim.

\section{OPEN ACCESS}


DR SARAH JADUN (Orcid ID : 0000-0002-8957-5809)

PROFESSOR JULIAN YATES (Orcid ID : 0000-0002-8187-023X)

Article type : Original Article

Patient Awareness and Quality of Oral Surgery Referrals to Specialist Practice

Dr Sarah Jadun ${ }^{1}$, Dr Nasser Syed ${ }^{2}$, Dr Tariq Drabu ${ }^{3}$, Professor Julian Yates ${ }^{1}$

${ }^{1}$ University Dental Hospital of Manchester, Higher Cambridge Street, Manchester M15 6FH

${ }^{2}$ SimplyOne Dental, 36 Queens Walk, The Precinct, Droylsden, Lancashire M43 7AD

${ }^{3}$ Langley Dental Practice, 215a Wood Street, Middleton, Manchester M24 5RU

Corresponding author -

This article has been accepted for publication and undergone full peer review but has not been through the copyediting, typesetting, pagination and proofreading process, which may lead to differences between this version and the Version of Record. Please cite this article as doi: 10.1111/ORS.12467

This article is protected by copyright. All rights reserved 
Dr Sarah Jadun

University Dental Hospital of Manchester

Higher Cambridge Street

Manchester

M15 6FH

E-mail: sarahjadun@yahoo.co.uk

\section{Abstract \\ Introduction}

Recent years have shown an increase in the number of patients referred from primary care to a secondary care setting for oral surgery treatment. Due to the high volume of referrals to specialist Oral Surgery services, it is paramount that the referrals from dentist to specialists be appropriate and of a high standard.

\section{Materials and methods}

The first part of this study assessed patients referred to 2 primary care settings for oral surgery procedures in Manchester, UK, and the second part examined the quality of the referrals undertaken.

\section{Results}

A total number of 500 referrals were evaluated from January 2016 to June 2016 . The average waiting times for the patients was 3-4 weeks. The majority of patients understood why they had been referred and for what treatment. Less than half the patients were aware that they were to be treated under local anaesthetic. A significant number thought they would be treated either under IV sedation or GA. More than half the patients expected the treatment to be performed in a general dental practice although a number thought treatment would be undertaken in a hospital setting. The contact details were correct in $99 \%$. The teeth to be treated were also largely correct for both practices (98\%). Importantly, inappropriate radiographs were attached to more than half of the referrals.

\section{Conclusion}

This article is protected by copyright. All rights reserved 
A patient-centred approach to specialist referrals would better equip patients to make informed decisions regarding the treatment to be provided. Furthermore, clarification of referrals to Oral Surgery services is required in some cases.

\section{Key words:}

Oral surgery, primary care, secondary care, specialist referrals, patient awareness. 


\section{Introduction}

The healthcare system in the United Kingdom (UK) is organised with primary care services (dental practice setting) acting as gatekeepers to secondary care (non-practice/hospital setting). This is recognised as an appropriate and effective model for the efficient use of expensive, high technologyspecialist medical services. ${ }^{1}$ The same mechanism applies to dental services, as secondary dental care services are often a limited resource, with many services being heavily oversubscribed. It is therefore crucial to make the referral pathway to these services as effective as possible, preserve them for those patients who need them the most, and allow patients to be managed in the most appropriate environment.

Recent years have shown an increase in the number of patients referred from primary care to a secondary care setting for oral surgery treatment. Part of the reason could be attributed to a significant rise in the population within the UK over the past 20 years, with the population increasing by almost 10 million in this period. ${ }^{2}$ Another potential reason for the increase in demand for oral surgery services is because patients keep their teeth longer, and elderly patients often have other medical conditions that make their care more complex. ${ }^{3}$ Another potential contributing factor is the increased risk of litigation making attempts at treatment by primary care clinicians prohibitive, and referral a much safer option. Following the introduction of the 2006 National Health Service (NHS) dental contract, there was a sharp rise in oral surgery referrals, partly driven by the structure of the contract, which remunerated dentists the same fee to refer a patient as to undertake the procedure themselves. A study conducted by Goldthorpe et al (pp3) found 670 referrals received from dental practices in Merseyside in 2014, demonstrating a significant increase in referrals in $2006 .{ }^{4}$ Other factors that may drive referral rates include a lack of oral surgery experience at the undergraduate level among junior dentists translating to reduced skills within dental practice, working environment and allied pressures relating to other treatments and patient choice.

In response to this increased demand for oral surgery services in the National Health Service, the NHS England Oral Surgery Commissioning Guide was published in 2015. This guide described the levels of case complexity that can be addressed in settings such as primary and secondary care. ${ }^{5}$ The commissioning guide reflects the needs and complexities of patient care and the competency of the clinician required to deliver the clinical intervention, thereby allowing commissioners to manage

This article is protected by copyright. All rights reserved 
resources appropriately. ${ }^{5}$ However, the commissioning guide provides no relevant information for the public or for healthcare users. In parallel with this guidance a referral management system was also commissioned under the Dental Quality, Innovation, Productivity and Prevention (QuIPP) programme, developed by the UK Department of Health. ${ }^{6}$ This referral management system was also accompanied by a primary care-based oral surgery service to deliver advanced primary care treatments. The aim of this system was to reduce the number of inappropriate oral surgery referrals to secondary care by selecting cases that could be safely treated in a primary care setting by dentists with additional skills or appropriate compitencies. ${ }^{4}$ This system advocates the wider use of primary care settings for advanced or specialist led care, with access to consultant led advice, supervision and treatment when needed, thereby providing a pathway consistent with the Oral Surgery Commissioning Guide. ${ }^{7}$

Oral surgery referrals represent the largest volume and most costly referrals from primary dental care to secondary care. ${ }^{8}$ Oral surgery referrals are primarily for tooth extractions (surgical and non-surgical), or medically related issues, and may be supplemented with a request for sedation or general anaesthesia (GA) due to patient anxiety and/or the complexity of the procedure required. ${ }^{9}$ Secondary care dental services are commonly (although not exclusively) provided in a hospital setting and is usually consultant-led with trainees at various levels undertaking procedures. A study conducted by Halai and Yates in 2014 detailed that the majority of referrals to secondary care were for surgical, multiple or difficult extractions. ${ }^{10}$ Following referral, 56\% of extractions were provided under local anaesthetic, 34\% under intravenous (IV) sedation and 10\% under GA. ${ }^{10}$ The study also demonstrated that $53 \%$ of the referred patients had one or more documented medical conditions, whereas $47 \%$ were fit and healthy. ${ }^{10}$

The Department of Health Advanced Care Pathway Working Group defined procedures and patient modifying factors that describe the complexity of the case. ${ }^{5}$ The levels of complexity range from Level 1 to Level 3. Level 1 care described the skill set and competencies a dentist would possess on completion of undergraduate and dental foundational training, for example extraction of erupted teeth including uncomplicated third molars. Level 2 care is defined as a procedure and/or patient complexity that requires enhanced skills and experience. This level of care encompasses the surgical removal of third molars and buried roots, and minor soft tissue surgery. Level 3 includes procedures

This article is protected by copyright. All rights reserved 
or conditions that may be performed or managed by a specialist or a consultant. This level of care includes more complex procedures such as the those involving increased risk of complications such as nerve/vascular damage, displacement of fragments into the antrum or other tissue spaces and fracture of the mandible. Level 1 and 2 procedures can usually be performed in primary care settings, however some Level 1, 2 and 3 procedures may be performed in a secondary care setting if there are modifying patient and treatment factors. ${ }^{5}$

There are noted to be different dimensions to primary care referrals, including necessity of referral and the destination to which patients are referred to. Published literature demonstrates that a large number of referral letters lack the necessary information, and there is a lack of shared understanding of the purpose of the referral between the referring clinician, the patient and the consultant. Measurement of the quality of patient engagement in primary care has not been consistently useful or completely utilised in the past. There is limited published work on patient awareness regarding specialist dental referrals, however, there are some studies on patient awareness and choice regarding General Medical Practitioner (GMP) patient referrals to a specialist. The King's Fund conducted research on how patients experience choice with providers in four local health authorities in England between August 2008 and September 2009. ${ }^{11}$ Approximately half of patients were aware of their ability to choose, and $75 \%$ of the patients thought it was important that they were given that choice. This finding emphasises the need to involve patients in the decision-making process of their treatment, particularly as the model of patient choice requires that patients are aware of their input into the decision-making process. The authors are practising primary care oral surgeons, and we have become well aware of the lack of patient knowledge of this well-established referral pathway and decided that action was required. The first priority was to highlight specific gaps in patient knowledge and then help address these gaps with a well-constructed information leaflet.

Due to the high volume of referrals to Specialist Oral Surgery services, it is paramount that the referrals from dentist to specialist be of a high standard. Referring patients between health care providers is part of a complete quality health care approach. However, several published studies have demonstrated that the standards for oral surgery referrals are universally poor. A study conducted at Newcastle Dental Hospital in 2008, assessing the quality of external referrals for IV sedation, found that a medical history was found in only $59 \%$ of the referrals made. ${ }^{12}$ The findings indicated a need to 
improve the amount of information provided within the referrals. A good quality dental referral must contain all the necessary information for ensuring efficient and safe treatment without delaying diagnosis and treatment. ${ }^{13}$ A good quality referral eliminates time wasted and improves the patient (and clinician) experience. Referrals are often the main method of communicating confidential information between healthcare professionals, and complete and accurate referral avoids further unnecessary correspondence for clarification purposes.

To triage patients appropriately, information on clinical details and medical history, as well as administrative details are necessary. Incomplete referrals may lead to unnecessary delays in processing the referral, unnecessary exposure to ionising radiation and increased patient frustration and dissatisfaction with the healthcare system. Incomplete referrals may also delay the patient's treatment, leading to more complex procedures at a later date. It is therefore important that communication is efficient and contains appropriate information.

\section{Materials and methods}

Ethical approval was not required for this study. There were 2 components to this prospective study. The first part assessed patients referred to 2 primary care settings (general dental practice) for oral surgery procedures in Manchester (UK), including simple and surgical dental extractions, and third molar surgery. Patients were treated under local anaesthetic with or without IV sedation. Both practices were providers of Level 2 Oral Surgery services. The questionnaire was developed because many patients attending for minor oral surgery appointments were unaware of the reason for attendance. Patients were asked and voluntarily completed a questionnaire prior to their treatment. The questionnaire was then validated on 5 patients. 250 questionnaires were completed per practice, yielding a total of 500 questionnaires. The survey consisted of the following questions:

This article is protected by copyright. All rights reserved 


\section{Waiting time}

What was your waiting time from the time of referral to being seen by a surgeon?
a. 1-2 weeks
b. 3-4 weeks
c. 1-2 months
d. 3-4 months
e. Unsure

Reason for referral

Do you understand what you have been referred here for today?
a. Completely understand
b. Partly understand
c. Do not understand
d. Not discussed
e. Unsure

\section{Treatment modality}

How do you expect this treatment to be carried out?
a. Local anaesthetic (injection in mouth)
b. Inhalation sedation (happy air)
c. Intravenous (IV) sedation (awake but relaxed)
d. General anaesthetic (asleep)
e. Not discussed
f. Unsure

\section{Location of treatment}

When you were referred by your dentist, in which of the following locations did you think your treatment would be carried out: 

a. A dental practice
b. A local hospital
c. Not discussed
d. Unsure

The patients had been referred for specialist treatment by their general practitioner through a dental referral management company (FDS) service. Once the referral has entered the FDS system, it is then triaged by consultants in Oral and Oral and Maxillofacial Surgery and referred to the appropriate setting to be treated.

The second part of the study examined the quality of the referrals, and assessed whether the contact details on the referral were correct, whether the teeth to be treated were charted correctly, whether the medical history was accurate, whether the appropriate radiographs were attached, and whether, following consultation, the patient was referred to a secondary care setting.

\section{Results}

The completion rate was $100 \%$ for the questionnaires. No demographic data was acquired in this survey.

\section{Waiting time}

Table 1 demonstrates the waiting times for the treatment appointment for the patients. The average waiting times for the patients was 3-4 weeks (37\%), with only a minority (12\%) waiting 3-4 months. Both practices demonstrated similar waiting times.

\section{Reason for referral}

Patient understanding of the reason for referral is given in Table 2. The majority (79\%) of the patients completely understood why they had been referred, however, a significant number (18\%) only partly understood or did not understand why they had been referred to the practice. Some patients stated that the reason for referral had not been discussed with them at all (1\%).

This article is protected by copyright. All rights reserved 


\section{Treatment modality}

When considering treatment modality, the results are shown in Table 3. Less than half the patients (41\%) were aware that they were to be treated under local anaesthetic, with more patients (63\%) in practice 2 being aware of this. Many thought they would be treated either under intravenous (IV) sedation (14\%) or general anaesthetic (GA) (8\%). However, many patients were unsure or stated that the treatment modality had not been discussed (35\%).

\section{Location of treatment}

The results for the expected location for treatment are shown in Table 4. Many of the patients expected the treatment to be performed in a general practice (44\%), but a large number expected to be treated in a hospital setting (34\%).

\section{Quality of referral}

The contact details were correct in 99\% (498) of the referrals, with equal numbers being correct for both practices. The teeth to be treated were also mostly correct for both practices $(98 \%)$. Practice 1 found medical histories to be incorrect in 2\% (9) of referrals, and 11\% (25) in practice 2. Inappropriate radiographs were attached to more than $55 \%$ (151) of the referrals to practice 1 , and $30 \%$ (69) of referrals to practice 2 . In total $7 \%$ (36) of the patients were referred to secondary care to be treated (Figure 1).

\section{Discussion}

In England, as part of the NHS Constitution, patients have the "right to access certain services commissioned by the NHS bodies within maximum waiting times, or for the NHS to take all reasonable steps to offer a range of suitable alternative providers if this is not possible". ${ }^{14}$ The NHS Constitution states that patients should not wait any longer than 18 weeks from General Medical or Dental Practitioner referral to treatment. This study shows that $95 \%$ of patients were seen and treated within 18 weeks, with the remaining 5\% being unsure of exactly how long they had been waiting. The majority of the patients were seen within 3-4 weeks of the referral entering the referral management system. The results are therefore largely within the 18-week referral to treatment (RTT) pledge, and

This article is protected by copyright. All rights reserved 
also within the accepted threshold of $92 \%$ of patients. This waiting time begins when any healthcare professional or service permitted by an English NHS commissioner to make such referrals, refers a patient to a consultant-led service regardless of the setting, or an interface or referral management service which may result in an onward referral to a consultant led service. ${ }^{15}$ There are clinical exceptions to this rule. These exceptions include those patients who choose to wait longer than 18 weeks if it is in the patients' clinical interest, cases when it has been difficult to reach or contact the patient or delays due to a series of diagnostic medical tests. In this case, all patients were treated within 18 weeks of initial referral, therefore the 18 -week target was being met. A study conducted by Kendall in 2011 also demonstrated this reduced waiting time for patients in primary care oral surgery services, with the study demonstrating the waiting time in primary care to average between 3 and 6 weeks from referral to actual treatment. ${ }^{9}$ This referral to primary care not only reduces waiting times but also improves access to oral surgery services and engages oral surgery specialists in a general practice setting.

In accordance with the guidance of the UK's General Dental Council (GDC), all patients must be fully aware of all aspects of the treatment being provided. From this study, it can be seen that this is not always the case. Seventeen percent of patients partly understood the reason for their referral and $2 \%$ did not understand or stated that the reason had not been discussed at all. This lack of understanding can easily be overcome through a thorough explanation, with additional documentation provided to the patient explaining the reasoning for the referral. This method can also be used to discuss the treatment modality and location of the referral. Fewer than half of the patients (41\%) were aware that they would be treated under local anaesthetic, and $8 \%$ believed the treatment would be performed under GA. This confusion may be the result of a variety of factors. Patients may be given large volumes of information that may be difficult to retain, or they may not be given any information at all, with the prospect of referral being an afterthought once the patient has left the surgery.

Providing written information allows the patient time to think and reflect about the upcoming treatment, and to decide whether they wish to undergo the treatment at all. Informative and patientfriendly leaflets relating to specific oral surgery procedures can be created by the practice itself (Figure 2 demonstrates an example), or downloaded from the British Association of Oral Surgeon (BAOS) website and given to patients at the initial appointment with their general dental 
practitioner. ${ }^{16}$ After such an informative initial consultation, the patient can attend the Level 2 service with confidence and assurance in the proposed course of treatment. The treating oral surgeon will confirm the treatment and clarify any specific risk relating to the procedure in order to assure that informed consent has been achieved.

Patient centred care (PCC) and giving patients a choice relating to decisions regarding their health have been popular ideas in medical and dental settings. ${ }^{17}$ Within these settings, PCC has been defined as a process in which the care provided is respectful of and responsive to individual patient preferences, needs and values, ensuring that patient values guide all clinical decisions. This PCC places the patient at the forefront of all decision-making regarding treatment. Research conducted by health services suggests that PCC enhances patient satisfaction and health status, improves clinical outcomes and reduces the use of care. ${ }^{18}$ Research also states that PCC can result in greater work satisfaction for healthcare professionals and lower levels of medical and dental litigation. ${ }^{19}$ These benefits are extremely desirable for patients, healthcare professionals and commissioners.

The UK NICE guidance proposed fourteen principles to make the experience of adults using the NHS more patient-centred. ${ }^{20}$ These principles encourage patients to be actively involved in shared decision-making about treatment. The UK GDC Standard for Dental Professionals also outlines principles that dental professionals should follow. Within this document, Standard 2 is about "communicating effectively with the patient", giving the patient clear and accurate information before treatment so the patient can make informed decisions in partnership with the clinicians providing their care. $^{21}$

Although both the academic literature and recommended practice endorse PCC, there may be a lack of understanding by dental professionals about how to incorporate this into day-to-day clinical practice. A recent review of PCC in the dental literature demonstrates a lack of understanding of what PCC means in the dental profession. This lack of understanding may be due to the fact that the term "patient-centred" is used as a purely descriptive term, with little consideration to its meaning, or to the context in which it is used..$^{15}$ This can create confusion for healthcare professionals, where there may be varied opinions on what successful patient-centred care is.

The British Association of Oral Surgeons has placed great importance on the provision of routine oral surgery in primary care dental services, which would enable patients to receive high- 
quality treatment locally, with reduced waiting times. ${ }^{22}$ However, as part of "high-quality treatment" and the process of patient centred care, patients must be fully informed regarding the decisions made about their treatment. Ways of improving patient awareness would include a thorough discussion with the patient during treatment planning and allow the patient to take home literature to read and process the information discussed during the consultation.

The overall standard for basic administrative details was good, with many of the referrals containing satisfactory information. This finding agrees with previous work conducted by Newton in 1992 and McAndrew in 1997. ${ }^{23,24}$ The use of proforma forms aids the input of such details as the treatment team may otherwise rejects the referral. Many of the referrals in both practices did not contain sufficient information regarding patient medical history. This oversight can pose a high risk to patient safety, especially if the patient has been triaged into the wrong setting based on the information provided. A medical history including past and present medications helps prevent polypharmacy and encourages safer prescribing, in addition to assisting the specialist in creating a treatment plan without additional 'time-wasting' correspondence with the referring practitioner. ${ }^{25}$ One study found that only $58 \%$ of referral letters gave an accurate list of medications and drug doses used by their patients. ${ }^{26}$ Furthermore, it has been shown that medical information provided by general dental practitioners (GDPs) is of inferior quality compared to that provided by general medical practitioners (GMPs). ${ }^{27}$ Inadequacy of GDP referrals could be due in part to a general perception among the public that GDPs do not need to know their patients' medical history, and so some patients will not disclose information which may be of relevance. ${ }^{28}$

Pre-operative radiographs are a necessity for most elective dentoalveolar surgical procedures. Previous studies have shown that referrals for wisdom teeth surgery often lack appropriate radiographs. ${ }^{29}$ Appropriate radiographic assessment is necessary for anticipating the difficulty and planning the surgical approach. This study shows that inappropriate radiographs were included with $44 \%$ of referrals. Panoramic radiographic radiographs are required for wisdom teeth surgery in order to assess proximity to nerves and root anatomy. To adhere to the "as low as reasonably achievable" principle, repeated exposure to radiation is undesirable. One solution to this issue would be to demand a panoramic radiograph prior to the referral being sent. Many referrers may feel apprehensive about prescribing radiographs for procedures they do not intend to perform themselves. ${ }^{30}$ This apprehension

This article is protected by copyright. All rights reserved 
may explain why simple extraction referrals more often contain appropriate radiographs, as plain film radiographs are usually sufficient for the initial assessment. Appropriate medical history and radiograph inclusion may therefore have prevented referral to secondary care, as seen in this study. The triaging team may then be able to assess the complexity of the care appropriately.

\section{Conclusion}

Patient awareness regarding specialist oral surgery referrals has not been thoroughly investigated in the literature. This gap in knowledge raises the question of whether patient preferences regarding such referrals are considered. Although the quality of referrals has previously been investigated, there does not seem to have been an improvement in referrals to such a service from GDPs. A patient-centred approach to specialist referrals would better equip patients to make informed decisions regarding the treatment to be provided.

\section{Declaration of interests}

The authors have no conflicts of interest to declare.

\section{Clinical Relevance}

\section{Scientific rationale for study}

Recent years have shown an increase in the number of patients referred from primary care to a secondary care setting for oral surgery treatment. Due to this increase, it is crucial that primary care dentists refer appropriately in order to fully utilise secondary care resources to treat only those who require it. Patients must also be fully aware regarding the reason for referral to a different setting and/or specialist clinician.

\section{Principal findings}

A total number of 500 referrals were evaluated from January 2016 to June 2016. TThe majority of patients understood why they had been referred and for what treatment. Less than half the patients were aware that they were to be treated under local anaesthetic. A significant number thought they would be treated either under IV sedation or GA. More than half the patients expected the treatment to be performed in a general dental practice although a number thought treatment would be undertaken

This article is protected by copyright. All rights reserved 
in a hospital setting.

\section{Practical implications}

This study demonstrates that dentists must take a patient centered approach, and fully inform patients regarding rationale behind referral, in order to obtain valid consent. Clinicians must involve the patients more in the decision making process behind their treatment.

\section{References}

1. Bowling A, Redfern J. The process of outpatient referral and care: the experiences and views of patients, their general practitioners, and specialists. Br J Gen Pract 2000; 50: 116-120.

2. Worldometers. U.K. Population. 2018. Online information available at: http://www.worldometers.info/world-population/uk-population/.

3. NIHR DC Discover.. Redesigning oral surgery with enhanced primary dental care, electronic referral and triage may save overall costs. NIHR Dissemination Centre, 2018.

4. Goldthorpe J, Walsh T, Tickle M et al. An evaluation of a referral management and triage system for oral surgery referrals from primary care dentists: a mixed-methods study. Health Serv Deliv Res 2018; 6: 1-126.

5. BAOS. Guide for commissioning oral surgery and oral medicine. London, UK: BAOS, 2015.

6. Smith S. QIPP programme (quality, innovation, productivity and prevention). London, UK: The Lancet, 2012.

7. NHS England. Introductory guide for commissioning dental specialties. London, UK: NHS England, 2015.

8. O'Neill E, Gallagher J E, Kendall N. A baseline audit of referral and treatment delivered to patients in the intermediate minor oral surgery service in croydon PCT. Prim Dent Care 2012; 19: 23-28.

9. Kendall N. Development of oral surgery services in primary care. Oral Surg 2011; 4: 57-64.

This article is protected by copyright. All rights reserved 
10. Halai T, Yates J M. Assessment of oral surgery referrals from primary care to a regional dental hospital. Oral Surg 2014; 7: 168-176.

11. Dixon A, Robertson R, Appleby J, Burge P, Devlin N, Magee H. Patient choice-how patients choose and how providers respond. London, UK: The King's Fund, 2010.

12. Dentith G E, Wilson K E, Dorman M, Girdler N M. An audit of patient referrals to the sedation department of newcastle dental hospital. Prim Dent Care 2010; 17: 85-91.

13. Izadi M, Gill D S, Naini F B. A Study to assess the quality of information in referral letters to the orthodontic department at kingston hospital, surrey. Prim Dent Care 2010; 17: 73-77.

14. NHS Clinical Services Team. Referral to treatment consultant-led waiting times: rules suite. London, UK: NHS Clinical Services Team, 2015.

15. Scambler S, Delgado M, Asimakopoulou K. Defining patient-centred care in dentistry? A systematic review of the dental literature. Br Dent J 2016; 221: 477-484.

16. British Association of Oral Surgeons. Patient information leaflets. 2018. Online information available at http://www.baos.org.uk/patient-leaflets/.

17. Newton P, Asimakopoulou K G. Response to Professor Anderson's commentary on Empowerment article by Asimakopoulou, K. Eur Diabetes Nurs 2008; 5: 36-36.

18. Stewart M, Brown J B, Donner A et al. The impact of patient-centered care on outcomes. $J$ Fam Pract 2000; 49: 796-804.

19. Irwin R S, Richardson N D. Patient-focused care. Chest 2006; 130: 73S-82S.

20. NICE. Patient experience in adult NHS services: improving the experience of care for people using adult NHS services: clinical guidelines (CG138). London, UK: NICE, 2012.

21. General Ddental Council. Standards for the dental team. 2013. Online information available at www.gdc-uk.org.

22. British Association of Oral Surgeons. BAOS review of oral surgery dental programme board of NHS medical education England (NHS MEE) consultation exercise. BAOS, 2009.

23. Newton J, Eccles M, Hutchinson A. Communication between general practitioners and consultants: what should their letters contain? BMJ 1992; 304: 821-824.

24. McAndrew R, Potts A J, McAndrew M, Adam S. Opinions of dental consultants on the standard of referral letters in dentistry. Br Dent $J$ 1997; 182: 22-25.

This article is protected by copyright. All rights reserved 
25. Lang M, Selvadurai T, Zakrzewska J M. Referrals to a facial pain service. Br Dent J 2016; 220: $345-348$.

26. Carney S L. Medication accuracy and general practitioner referral letters. Intern Med J 2006; 36: $132-134$.

27. DeAngelis A F, Chambers I G, Hall G M. The accuracy of medical history information in referral letters. Aust Dent J 2010; 55: 188-192.

28. Edwards J, Palmer G, Osbourne N, Scambler S. Why individuals with HIV or diabetes do not disclose their medical history to the dentist: a qualitative analysis. Br Dent $J$ 2013; 215: E10.

29. Liedholm R, Henricsson V, Lysell L et al. Patient flows in the care process of mandibular third molar surgery. Swed Dent J 2005; 29: 97-104.

30. Renton T, McGurk M. Direct referral day case oral surgery for dental practitioners: a pilot investigation. Br Dent J 1999; 186: 334.

This article is protected by copyright. All rights reserved 
Tables

Table 1. Results of patient waiting time.

\begin{tabular}{|l|l|l|l|}
\hline Waiting Time & Practice 1 & Practice 2 & Total \\
\hline 1-2 weeks & 35 & 42 & 77 \\
\hline 3-4 weeks & 86 & 100 & 186 \\
\hline 1-2 months & 105 & 48 & 153 \\
\hline 3-4 months & 35 & 23 & 58 \\
\hline Unsure & 11 & 15 & 26 \\
\hline Total & 272 & 228 & 500 \\
\hline
\end{tabular}

Table 2. Results of patient understanding regarding their referral.

\begin{tabular}{|l|l|l|l|}
\hline $\begin{array}{l}\text { Patient } \\
\text { Understanding }\end{array}$ & Practice 1 & Practice 2 & Total \\
\hline $\begin{array}{l}\text { Completely } \\
\text { understand }\end{array}$ & 214 & 183 & 397 \\
\hline Partly understand & 51 & 33 & 84 \\
\hline Do not understand & 2 & 2 & 4 \\
\hline Not discussed & 0 & 5 & 5 \\
\hline Unsure & 5 & 5 & 10 \\
\hline Total & 272 & 228 & 500 \\
\hline
\end{tabular}

This article is protected by copyright. All rights reserved 
Table 3. Results of treatment modality expected by patient.

\begin{tabular}{|l|l|l|l|}
\hline $\begin{array}{l}\text { Treatment } \\
\text { modality }\end{array}$ & Practice 1 & Practice 2 & Total \\
\hline Local anaesthetic & 62 & 144 & 206 \\
\hline Inhalation sedation & 7 & 4 & 11 \\
\hline IV sedation & 63 & 6 & 69 \\
\hline General anaesthetic & 36 & 4 & 40 \\
\hline Not discussed & 31 & 32 & 63 \\
\hline Unsure & 73 & 38 & 111 \\
\hline Total & 272 & 228 & 500 \\
\hline
\end{tabular}

Table 4. Results of patient expectation of treatment setting.

\begin{tabular}{|l|l|l|l|}
\hline $\begin{array}{l}\text { Treatment } \\
\text { location }\end{array}$ & Practice 1 & Practice 2 & Total \\
\hline Dental practice & 136 & 82 & 218 \\
\hline Hospital & 67 & 104 & 171 \\
\hline Not discussed & 22 & 17 & 39 \\
\hline Unsure & 47 & 25 & 72 \\
\hline
\end{tabular}

This article is protected by copyright. All rights reserved 


\section{Figures}

Figure 1. Quality of the referrals to primary care oral surgery services.

Figure 2. Example of a patient leaflet.

This article is protected by copyright. All rights reserved 


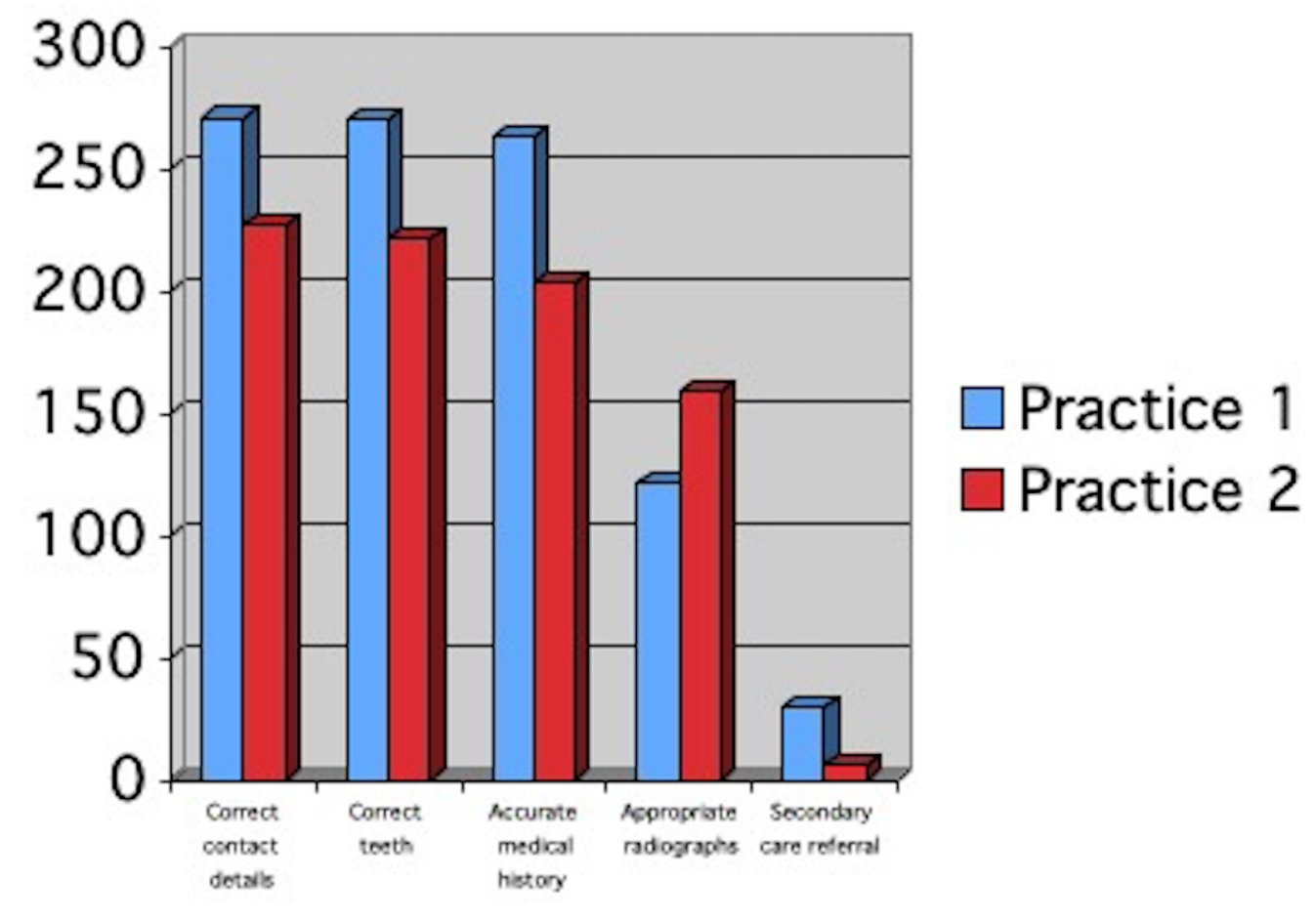

ors_12467_f1.jpg 


\section{ORAL SURGERY REFERRAL PATIENT INFORMATION LEAFLET}

\section{Dear SiriMadam}

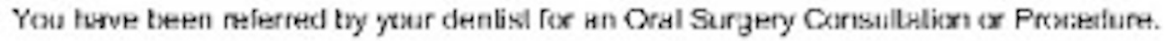

Your referral letter has boen sent to the Greater Manchester Dental Referral Management Centre where it wit be assassed and then sent to a suirable trestment centre. This means you may be seen in a dental practice or at a hospital depending on spacialist treatment you nead.

You should be aware of the following-

- This eyetom has bocn croatod to onsuro thas pationts got the trcatmont that they nood ae quicky as possible.

- Ycur dentisa wil have explained to you haw you will have your trealment dxe -

- Local ansesthetic - just numbing the area w th injections in your mouth

2. Local ansesthetic with sedation - numbing the area and sedation (relaxed but NOT asleep)

c Gcncral anacsithcic - fully asalexp (unconsoksus)

This is important hecause this wil help deride where youx treatment will be undertaken.

- Once your referral has been recelved you zil be ghen a unlque reference number (URN) for your referral. You can track your referral online by visiting:

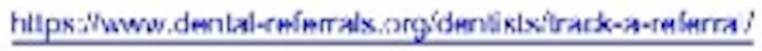

- Please make sure that all your contact details are up to date an your clertal practice because these are t.sed lo conlatil you ard arrange your appoint nert.

- If you are sent to have your treatment at a dental practice you will be treated by a dentist with sulfible expertise and experience in Oras sugery. Your sasfely is bux prionity.

- If you are referred to have your Oral Surgery procedure completed at a dental practice you MAY be offered a consultation or treatment at your first appointment. If you are at all unsure please check with the practice when you phone to arrange your appointment.

- Please bring a list of medications (e g. a repeat prescriotion) that you have been prescribed with you to youx tirst appointment.

- Onces your treatmeny. is completed you will be dischurged back to the practice thest referred you for your general dental care.

YOUR URN NUMBER IS

ors_12467_f2.jpg

This article is protected by copyright. All rights reserved 